\title{
Factors Influencing Extent of Opinion Leadership of Farm Women in Himalayan Regions of Uttarakhand, India
}

\section{Neelam Basera}

School of Agriculture, Graphic Era Hill University, Dehradun, Uttarakhand, India

*Corresponding author: neelambasera90@gmail.com (ORCID ID: 0000-0003-0855-9776)

Paper No. 941

Received: $14-09-2021$

Revised: 23-11-2021

Accepted: 07-12-2021

\begin{abstract}
The use of social network theories dates back to 1930s. With the advent of new and advanced technologies, there has been an explosion and expansion of its applications to various disciplines. The study applies social network theory and analysis to analyze agricultural knowledge exchange and decision-making network of farm women. The analysis detects farm women who occupy central and strategic positions and acts as opinion leaders in the network. It also identifies the factors which influences their extent of opinion leadership. The study was carried out in the Himalayan regions of Uttarakhand state in northern India. Descriptive research design and multi-stage sampling were adopted. Data were collected through survey sociometric method and UCINET was used for analysis and interpretations of network data. Degree centrality was used to identify opinion leaders within the network. SPSS was used to analyze the relationship between dependent and independent variables. Using network analysis, twenty four opinion leaders were identified among the farm women. Their extent of opinion leadership was influenced by age, marital status, farming experience, socio- economic status, innovativeness, achievement motivation, decision making ability, risk preference, economic motivation, information seeking behaviour, cosmopoliteness and social participation.

\section{HIGHLIGHTS}

( Social network analysis can be applied to identify network roles like stars, leaders, connectors, gatekeepers and liaisons, etc.

(- Opinion leaders may acts as a bridge between the farming world and the technological platforms.

( Network centrality particularly degree centrality may be used to identify opinion leaders in a network.

( The extent of opinion leadership exhibited by opinion leaders may vary from individual to individual while strong opinion leadership is concentrated among few.

( Socio-economic, personal, psychological and communication characteristics affects the extent to which opinion leadership is exhibited by opinion leaders.
\end{abstract}

Keywords: Network centrality, Degree centrality, Opinion leadership, Network analysis, Farm women

In context of Uttarakhand, one of the northern states in India, most effective and leading workforce is of women, visible in every walk of life from agriculture to small industry. Women in these mountainous regions are responsible for both farm and home management as men have migrated to plain areas in search for better educational and employment opportunities. They showed more dependency on interpersonal channels of communication than mass media and other cosmopolite channels of communication in the study area. Although

How to cite this article: Basera, N. 2021. Factors Influencing Extent of Opinion Leadership of Farm Women in Himalayan Regions of Uttarakhand, India. Int. J. Ag. Env. Biotech., 14(04): 535-541.

Source of Support: None; Conflict of Interest: None (a) क्ष 
mass media channels have been widely utilized for dissemination of useful information, it only creates awareness. It is the interpersonal channels of communication which influences the actions and decisions of others, resulting in patterned flow of communication. As studied by King and Bembridge (1988), it is within these informal networks where key individuals who are often named as opinion leaders operates, and acts as the only credible source for knowledge exchange and decision-making.

Opinion leaders prove to be potential advantage to extension in areas where formal agricultural support system is inadequate. The information diffusion and knowledge exchange by opinion leaders reaches to comparatively more number of farmers and thus, improves farming efficiency as pointed by Bembridge (1986). Thus, the orientation of development has shifted to inclusion of farm women who performs the roles of leaders and affects the agricultural knowledge exchange and decision making process. As stated by Merwe and Heerden (2009) the identification of opinion leaders can be simplified through the use of social network theories. Social network theories have been applied to measure the structural importance of actors as well as indicate central actors within the relational networks (Borgatti, 2006). However, the degree to which opinion leadership is exhibited by these central actors varies from individual to individual. Therefore, the extent to which opinion leadership is exhibited by the identified opinion leaders was measured. The socio-economic, personal, psychological and communication characteristicsof opinion leaders and theirrelationship with the extent of opinion leadership was also studied and explained.

\section{Research Methodology}

The study was conducted in Uttarakhand, a hill state, located in the central part of the Indian Himalayas. Nine of the thirteen districts of the state are mostly mountainous while the remaining four southern most districts consists of substantial portions that are mainly plains. Though the inner mountain region is rich in biodiversity, but is generally regarded as remote, highly fragile and undoubtedly marginal. The study followed descriptive research design and multi stage sampling procedure for the selection of respondents.
Village Badiyakot from Kapkot block of district Bageshwar and village Sabli Talli from Chamba block of district Tehri Garhwal were selected using simple random sampling without replacement. A total of 298 farm women were purposively selected as respondents i.e. 177 respondents from village Badiyakot and 121 respondents from village Sabli Talli and surveyed. The respondents were selected based on following criteria:

1. Farm women who were extensively involved in agriculture and allied activities.

2. Farm women who were above the age of eighteen years.

The quantitative information was collected through semi-structured interview schedule pre-tested and modified accordingly based on pilot study. Faceto-face interaction sessions with the respondents were conducted, sociometric question were asked and sociometric data were collected. Sociometric or "who -to whom" questions was the technique of choice for collecting network data. The data collected were coded, tabulated, analyzed and interpreted with UCINET (6.05) and SPSS. UCINET (Version 6.05) is a Windows software package developed by Steve Borgatti, Martin Everett and Lin Freemanin (2002). It was used for the analysis of network data to calculate In degree centrality of respondents. Based on their network (degree) centrality, farm women were categorized under three categories i.e. high, medium and low. Farm women under high categories were identified as respondent with more structural importance and role significance within the network.

\section{RESULTS AND DISCUSSION}

\section{Measurement of In degree centrality to identify opinion leaders}

To identify opinion leaders, most empirical network studies have focused on finding individuals who have high In degree centrality because it is more likely that people seek advice from individuals who have higher In degree centrality and, therefore, these individuals could affect other people's actions and decision making (Kim et al. 2007). Consequently, opinion leaders were identified as those farm women who belonged to high category of In degree centrality in the two villages. The findings presented in Table 1, concluded that high In degree centrality 
were recorded by 6.78 per cent and 9.92 per cent of the farm women in village Badiyakot and Sabli Talli respectively. Total twenty four respondents, twelve from each village and were recognized as opinion leaders based on their high In degree centrality.

\section{Extent of opinion leadership of the opinion leaders}

The dependent variable 'Extent of opinion leadership' was operationalized as the degree to which the opinion leaders are able to influence the agricultural knowledge exchange and decision making process in the study villages. As stated by Freeman (1979), network centrality reflects importance of individuals based on one's position within network relative to others and may be used to assess opinion leadership. Therefore, for the purpose of measurement of extent of opinion leadership of opinion leaders, In degree centrality was obtained for the opinion leaders on the basis of number of choices from fellow farm women in the village on a sociometric test. It was assumed that the number of people who nominated an individual reflected the amount of influence she has on them. Also, the more nominations one has from other, the higher In degree one has. This means that the lower the number of nominations, the weaker the extent of opinion leadership, while the higher the number of nominations, the stronger the extent of opinion leadership.

Based on the In degree centrality obtained by each opinion leader, opinion leadership was categorized

Table 1: Distribution of respondents on the basis of their network centrality $(n=298)$

\begin{tabular}{llllll}
\hline Village Badiyakot $\left(n_{1}=\mathbf{1 7 7}\right)$ & \multicolumn{5}{c}{ Village Sabli Talli $\left(n_{2}=\mathbf{1 2 1}\right)$} \\
\hline In degree centrality & $f$ & $\%$ & Category & $f$ & $\%$ \\
\hline Category & 8 & 4.52 & Low $(<0.27)$ & 10 & 8.26 \\
\hline Low $(<1.54)$ & 157 & 88.70 & Medium $(0.27$ to 9.92$)$ & 99 & 81.82 \\
Medium $(1.54$ to 14.57$)$ & 12 & 6.78 & High $(>9.92)$ & 12 & 9.92 \\
High $(>14.57)$ & &
\end{tabular}

${ }^{*} f=$ frequency, $\%=$ Percentage

Table 2: High network centrality of farm women in the sampled villages

\begin{tabular}{lll}
\hline Network Centrality & Sample villages & Respondent number with high network centrality in parentheses \\
\hline Degree centrality & & \\
\hline In degree centrality & Badiyakot & $58(47), 162(44), 129(44), 35(43), 24(40), 146(38), 103(33), 5(32), 71(27), 108(17)$, \\
& & $16(17), 119(15)$ \\
& Sabli Talli & $48(29), 61(22), 108(21), 34(19), 24(19), 68(17), 35(17), 13(16), 19(16), 80(15), 113(14)$, \\
& $90(14)$ \\
\hline
\end{tabular}
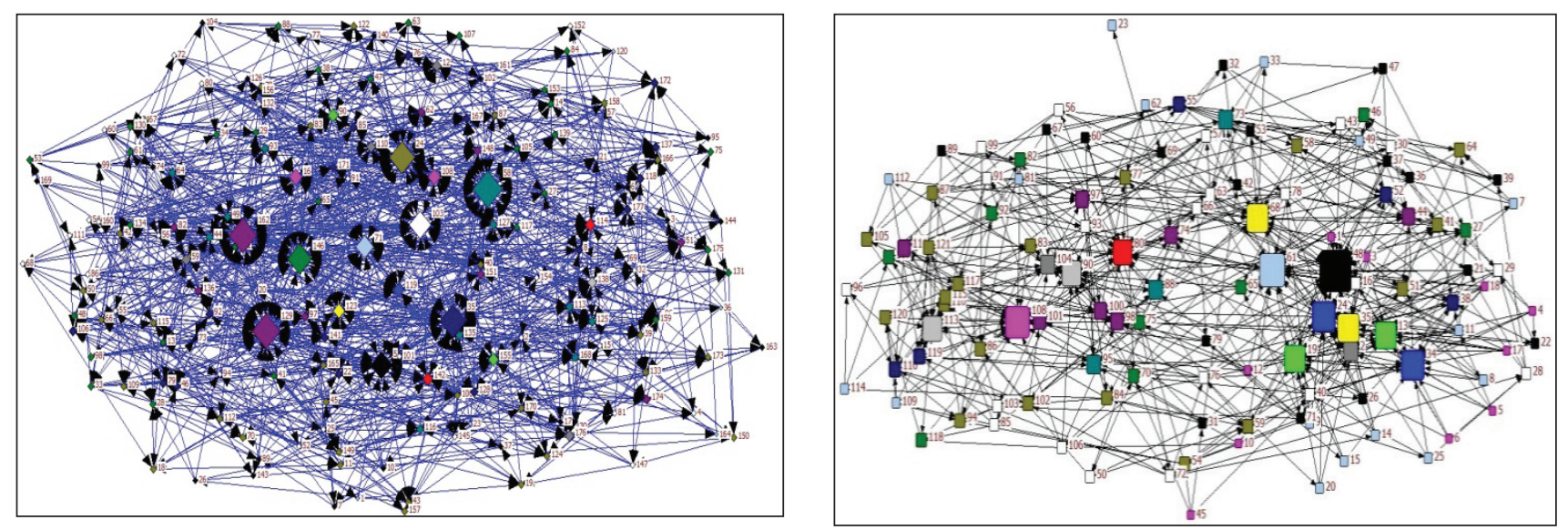

Fig. 1: Graph based on In degree centrality of farm women using NetDraw 
Table 3: Extent of opinion leadership among the identified opinion leaders ( $\mathrm{n}=24)$

\begin{tabular}{lllll}
\hline $\begin{array}{l}\text { S1. } \\
\text { No. }\end{array}$ & Extent of opinion leadership & f & $\%$ & $\begin{array}{l}\text { Respondent No. with corresponding In degree } \\
\text { centrality }\end{array}$ \\
\hline 1 & Low opinion leadership (14 to 25) & 14 & 58.34 & $\begin{array}{l}16(17), 119(15), 108(17), 35(17), 113(14), 108(21), 34 \\
(19), 80(15), 19(16), 90(14), 24(19), 68(17), 61(22), 13(16)\end{array}$ \\
2 & $\begin{array}{l}\text { Medium opinion leadership (25 } \\
\text { to 36) }\end{array}$ & 4 & 16.66 & $\begin{array}{l}5(32), 71(27), 103(33), 48(29) \\
3\end{array}$ \\
\hline
\end{tabular}

${ }^{*}=$ frequenc $y, \%=$ Percentage.

into high, medium and low categories using maximum score (47) minus minimum score (14) divided by three. The data in Table 3 indicates that maximum percentage of the opinion leaders $(58.34 \%)$ had low opinion leadership followed by 25 per cent of opinion leaders who had high opinion leadership. The remaining 16.66 per cent of the opinion leaders had medium level of extent of opinion leadership. This suggests that opinion leaders differ according to degrees of influence they exert on others in the network.

According to these findings, high opinion leadership was exhibited by one-fourth (25\%) of the opinion leaders and thus, qualified as strong opinion leaders with significant potential influence. The probable reason might be due to the fact that most of these opinion leaders were either more socially active or had maximum years of farming experience. Despite these, the relatively large percentage of opinion leaders about 58.34 per cent indicates low opinion leadership. This implies that many of the influence relationships are within either friendship or relatives circles/cliques and that these could perhaps be used to effectively mobilize the influence of opinion leaders.

\section{Socio-economic, personal, psychological and communication characteristics of opinion leaders}

It was observed that majority $(62.40 \%)$ of opinion leaders belonged to middle age category i.e. to the age group of 36 to 52 years, were married (83.33\%), educated up to primary school (41.67\%), belonged to upper caste (79.16\%) and had joint family (79.17\%) with 66.66 per cent of opinion leaders having medium family size (7 to 10 members). Being a mountainous state, Agriculture was the primary occupation of all the opinion leaders (100\%). About more than half of the opinion leaders i.e. 54.17 per cent performed animal husbandry followed by 20.83 per cent who were engaged in poultry farming as secondary occupation. As regards to farming experience, majority of the opinion leaders $(66.66 \%)$ had medium years of farming experience i.e. between 23 to 39 years. The socio-economic status of women is a critical factor which determines her social influence and importance. The findings indicates that majority of opinion leaders (70.84\%) belonged to medium socio-economic status followed by about one-fifth (20.83\%) of the opinion leaders who belonged to high socio-economic status. Only 8.33 per cent of the opinion leaders were from low socio-economic status.

The study on psychological and communication characteristics of the opinion leaders, reported that majority of the opinion leaders had medium level of innovativeness $(70.84 \%)$, scientific orientation $(70.84 \%)$, risk preference $(70.84 \%)$, achievement motivation $(75.00 \%)$, decision making ability $(70.84 \%)$ and economic motivation $(83.33 \%)$. Medium level of information seeking behavior was shown by majority $(70.84 \%)$ of the opinion leaders. It was realized that localite source of information were more frequently utilized by opinion leaders as compared to cosmopolite sources, mass media sources and extension education methods. Media ownership was found to be low among maximum percentage i.e. 58.33 per cent of opinion leaders. In terms of cosmopoliteness, maximum number of the respondents $(41.67 \%)$ reported medium level of cosmopoliteness. More than half of respondents $(58.33 \%)$ had medium level of social participation.

\section{Relationship between dependent and independent variables}

Coefficient of correlation was computed using Statistical Package for Social Sciences (SPSS, 2007) in order to find out the relationship between the 
Table 4: Characteristics of opinion leaders

\begin{tabular}{|c|c|c|c|c|c|}
\hline \multicolumn{3}{|c|}{ Socio-economic and personal characteristics } & \multicolumn{3}{|c|}{ Psychological and communication characteristics } \\
\hline Characteristics & $\mathrm{f}$ & $\%$ & Characteristics & $\mathrm{f}$ & $\%$ \\
\hline Age & & & Innovativeness & & \\
\hline Young ( $<36$ years) & 6 & 25.00 & Low $(<19.56)$ & 3 & 12.50 \\
\hline Middle (36-52 years) & 14 & 58.33 & Medium (19.56- 26.02) & 17 & 70.84 \\
\hline Old (>52 years) & 4 & 16.67 & High $(>26.02)$ & 4 & 16.67 \\
\hline Marital Status & & & Achievement Motivati & & \\
\hline Unmarried & 4 & 16.67 & Low $(<18.90)$ & 2 & 8.33 \\
\hline Married & 20 & 83.33 & Medium (18.90-27.86) & 18 & 75.00 \\
\hline Caste & & & High $(>27.86)$ & 4 & 16.67 \\
\hline General & 19 & 79.16 & Scientific Orientation & & \\
\hline OBC & 1 & 4.17 & Low $(<16.61)$ & 3 & 12.50 \\
\hline $\mathrm{SC} / \mathrm{ST}$ & 4 & 16.67 & Medium (16.61-24.63) & 17 & 70.84 \\
\hline Education & & & High $(>24.63)$ & 4 & 16.67 \\
\hline Illiterate & 0 & 0.00 & Risk Preference & & \\
\hline Can read only & 0 & 0.00 & Low $(<16.17)$ & 4 & 16.67 \\
\hline Can read and write & 8 & 33.33 & Medium (16.17-22.25) & 17 & 70.84 \\
\hline Primary & 10 & 41.67 & High $(>22.25)$ & 3 & 12.50 \\
\hline Middle & 5 & 20.83 & Decision-making Abil & & \\
\hline High school & 1 & 4.17 & Low $(<13.59)$ & 4 & 16.67 \\
\hline Graduate/ Post graduate & 0 & 0.00 & Medium (13.59-17.33) & 17 & 70.84 \\
\hline Family Type & & & High $(>17.33)$ & 3 & 12.50 \\
\hline Nuclear & 5 & 20.83 & Economic Motivation & & \\
\hline Joint & 19 & 79.17 & Low $(<18.84)$ & 1 & 4.17 \\
\hline Family size & & & Medium (18.84-24.58) & 20 & 83.33 \\
\hline Small $(<7)$ & 4 & 16.67 & High $(>24.58)$ & 3 & 12.50 \\
\hline Medium (7-10) & 16 & 66.66 & Media Ownership & & \\
\hline Large $(>10)$ & 4 & 16.67 & Low $(<2.03)$ & 10 & 41.67 \\
\hline Farming experience & & & Medium (2.03-3.73) & 7 & 29.17 \\
\hline Low $(<23.37)$ & 4 & 16.67 & High $(>3.73)$ & 7 & 29.17 \\
\hline Medium (23.37-38.70) & 16 & 66.66 & Cosmopoliteness & & \\
\hline High $(>38.70)$ & 4 & 16.67 & Low $(<4.19)$ & 8 & 33.33 \\
\hline Socio-economic status & & & Medium (4.19-6.89) & 10 & 41.67 \\
\hline Low $(<92.37)$ & 2 & 8.33 & High $(>6.89)$ & 6 & 25.00 \\
\hline Medium (92.37-121.71) & 17 & 70.84 & Social Participation & & \\
\hline $\operatorname{High}(>121.71)$ & 5 & 20.83 & Low $(<10.23)$ & 6 & 25.00 \\
\hline Occupation & & & Medium (10.23-14.69) & 14 & 58.33 \\
\hline None & 3 & 12.50 & High $(>14.69)$ & 4 & 16.67 \\
\hline Animal husbandry & 13 & 54.17 & Information seeking B & & \\
\hline Poultry farming & 5 & 20.83 & Low $(<24.97)$ & 2 & 8.33 \\
\hline Service & 1 & 4.17 & Medium (24.97-33.27) & 17 & 70.84 \\
\hline Business & 2 & 8.33 & High $(>33.27)$ & 5 & 20.83 \\
\hline
\end{tabular}

${ }^{*} f=$ frequenc $y, \%=$ Percentage. 
Table 5: Correlation between dependent and independent variables under study

\begin{tabular}{llll}
\hline S1. No. & Variables & $\begin{array}{l}\text { Calculated correlation } \\
\text { coefficient values " } \mathbf{r}^{\prime \prime}\end{array}$ & $\begin{array}{l}\text { Calculated significance value } \\
\text { "p" }\end{array}$ \\
\hline 1 & Age & $0.429^{*}$ & 0.037 \\
2 & Caste & $0.005^{\mathrm{NS}}$ & 0.982 \\
3 & Marital Status & $0.436^{*}$ & 0.033 \\
4 & Education & $-0.356^{\mathrm{NS}}$ & 0.088 \\
5 & Family Size & $0.326^{\mathrm{NS}}$ & 0.120 \\
6 & Family Type & $0.113^{\mathrm{NS}}$ & 0.599 \\
7 & Occupation & $0.255^{\mathrm{NS}}$ & 0.229 \\
8 & Farming Experience & $0.411^{*}$ & 0.046 \\
9 & Socio-economic status & $0.600^{* *}$ & 0.002 \\
10 & Innovativeness & $0.826^{* *}$ & 0.000 \\
11 & Achievement Motivation & $0.756^{* *}$ & 0.000 \\
12 & Scientific Orientation & $0.247^{\mathrm{NS}}$ & 0.245 \\
13 & Decision Making Ability & $0.552^{* *}$ & 0.005 \\
14 & Risk Preference & $0.476^{*}$ & 0.019 \\
15 & Economic Motivation & $0.614^{* *}$ & 0.001 \\
16 & Media Ownership & $0.076^{\mathrm{NS}}$ & 0.724 \\
17 & Information seeking Behaviour & $0.711^{* *}$ & 0.000 \\
18 & Cosmopoliteness & $0.638^{* *}$ & 0.001 \\
19 & Social Participation & $0.671^{* *}$ & 0.000 \\
\hline
\end{tabular}

NS: Non Significant; ${ }^{*}$ Correlation is significant at the 0.05 level (2-tailed); ${ }^{* *}$ Correlation is significant at the 0.01 level (2-tailed).

socio-economic, personal, and psychological and communication characteristics of the opinion leaders with their extent of opinion leadership. To explore the relationships, Pearson's product moment correlation co-efficient ( $\mathrm{r}$ ) has been used to test the hypotheses concerning the relationships between the independent and dependent variables.

Among the socio-economic, personal, psychological and communication variables under study, age, marital status, farming experience, socio-economic status, innovativeness, achievement motivation, decision making ability, risk preference, economic motivation, information seeking behaviour, cosmopoliteness and social participation were positively and significantly related to the dependent variable i.e. extent of opinion leadership. Age, marital status, farming experience and risk preference were significant at $5 \%$ level of significance whereas the remaining variables (socio-economic status, innovativeness, achievement motivation, decision making ability, economic motivation, information seeking behaviour, cosmopoliteness and social participation) were significant at $1 \%$ level of significance respectively. Based on the analysis, it was also noted that variables viz. caste, farm size, family type, occupation, scientific orientation and media ownership of opinion leaders had positive and non-significant relationship with the extent of opinion leadership. However, contrary to most of the studies, it was observed that educational status of opinion leaders had negative and non-significant relationship with the extent of opinion leadership.

\section{CONCLUSION}

The women in Himalayan regions need enrichment of their learning experiences as far as modern advancement in agricultural technology and knowledge exchange are concerned and opinion leaders stand by their side as immediate guide to help them. They stand as a bridge between the world of knowledge and the farming world. The identified opinion leaders can not only be trained but can be suitably employed to empower women.The study emphasized that though the importance of opinion leadership is bound to specifically vary according to situation, strong opinion leadership may be concentrated only to a few persons. It is, therefore, strongly recommended to include these opinion leaders at grassroots level, who work as catalyst to bring about the desired change in programme 
planning and its implementation. The findings of the study may provide guidance to policy makers and development planners, concerned about gender issues while designing agricultural projects within region or elsewhere in the country.

\section{ACKNOWLEDGEMENTS}

Authoress is grateful to Dr. Neelam Bhardwaj, Professor, Department of Agricultural Communication, G.B. Pant University of Agriculture and Technology for providing guidance and support to carry out this piece of work. I am also thankful to University Grant Commission in providing financial assistance which was of immense significance in conducting the research.

\section{REFERENCES}

Bembridge, T.J. 1986. An overview of agricultural and rural development problems in less developed areas of Southern Africa. Dev. Southern Africa, 3(1): 20-36.

Borgatti, S.P. 2006. Identifying sets of key players in a social network. Computational Mathematical and Organizational Theory, 12: 21-34.
Borgatti, S.P., Everett, M.G. and Freeman, L. 2002. UCINET for Windows: Software for Social Network Analysis. Harvard, MA: Analytic Technologies.

Borgatti, S.P., Everett, M. and Johnson, J.C. 2013. Analyzing social networks. $2^{\text {nd }}$ Ed. SAGE, London, England, pp. 45-54.

Freeman, L. C. 1979. Centrality in social networks: Conceptual clarification. Soc. Netw., 1(3): 215-239.

Freeman, L.C. 2004. The Development of Social Network Analysis: A Study in the Sociology of Science. Empirical Press, Vancouver.

Kim, D.K., Chitnis, K., Vasanti, P.N. and Singhal, A. 2007. Opinion Leadership Networks and Diffusion of e-Choupal in Indian Villages. J Creative Communi., 2(3): 345-360.

King, P.G. and Bembridge, T.J. 1988. An extension approach for the National Grazing Strategy based on farmer characteristics in the Eastern Cape. J Grassland Soc. of Southern Africa, 5(1): 8-14.

Merwe, R.V.D. and Heerden, G.V. 2009. Finding and utilizing opinion leaders: Social networks and the power of relationships. South African J. Business Mgt., 40(3): 65-75.

SPSS. 2007. Statistical packages for Social Sciences. Ver. 126, SPSS Inc., llinois, USA. 
